\title{
High tumor cell expression of microRNA-21 in node positive non-small cell lung cancer predicts a favorable clinical outcome
}

Helge Stenvold ${ }^{1,2^{*}}$, Tom Donnem ${ }^{1,2}$, Sigve Andersen ${ }^{1,2}$, Samer Al-Saad ${ }^{3,4}$, Andrej Valkov ${ }^{3,4}$, Mona Irene Pedersen ${ }^{1,4}$, Lill-Tove Busund ${ }^{3,4}$ and Roy M Bremnes ${ }^{1,2}$

\begin{abstract}
Background: MicroRNA (miR)-21 has been revealed as an oncogene in cancer development, and is one of the miRNAs closely connected to angiogenesis. We aimed to explore the impact of miR-21 expression in both tumor and stromal compartments of non-small cell lung cancer (NSCLC), and correlations between miR-21 and angiogenic protein markers.

Methods: From 335 unselected stage I to IIIA NSCLC carcinomas, duplicate tumor and tumor-associated stromal cores were collected in tissue microarrays (TMAs). In situ hybridization (ISH) was used to detect the expression of miR-21 separately in tumor cells and stromal cells of the tumor, and immunohistochemistry (IHC) was used to detect the expression of the protein markers protein kinase B (Akt), phosphatidylinositol-3-kinase (PI3K), hypoxia induced factor 1 (HIF1a) and vascular endothelial growth factor-A (VEGF-A).
\end{abstract}

Results: In univariate analyses, high tumor cell expression of miR-21 in patients with lymph node metastasis was a positive prognostic factor $(P=0.024)$. High stromal miR-21 expression had a negative prognostic impact $(P=0.022)$. In the multivariate analysis, low tumor mir-21 expression in node positive patients was an independent adverse prognostic factor (HR 2.03, Cl 95\% 1.09-3.78, P = 0.027).

Conclusions: In patients with lymph node metastasis, miR-21 expression in tumor cells is an independent positive prognostic factor. High stromal miR-21 expression is a negative prognostic factor.

Keywords: NSCLC, Stage I-IIIA, Survival, Prognostic impact, miR-21, miRNA

\section{Background}

Lung cancer is the leading cause of cancer-related deaths. NSCLC accounts for $80-85 \%$ of all lung cancers. New treatment strategies have so far had limited effect on lung cancer mortality [1]. Hence, research to identify new possible treatment targets is pivotal.

MicroRNAs (miRNAs) are small (19-22 nucleotides) non-coding RNAs. They play an important role in different cellular processes, such as regulation of proliferation, differentiation, apoptosis, development, metabolism, stress response and immunity [2,3]. It is assumed that

\footnotetext{
* Correspondence: Helge.Stenvold@uit.no

'Institute of Clinical Medicine, University of Tromso, Tromso, Norway ${ }^{2}$ Department of Oncology, University Hospital of North Norway, Tromso 9038, Norway

Full list of author information is available at the end of the article
}

approximately $30 \%$ of the genes are regulated by miRNAs [3]. The accruing prognostic data on miRNAs has made them interesting as potential therapeutic targets. Novel agents have not yet reached clinical trials, but there is considerable research going on in this field [4].

miR-21 is one of the most thoroughly studied miRNAs. Studies have revealed miR-21 as an oncogene [5], and in a recent meta-analysis miR-21 appeared as a negative prognostic factor [2]. It is also one of the miRNAs closely connected to angiogenesis [6,7]. In a recent study [8], we screened tissues from 10 worst and 10 best prognosis NSCLC cases as well as 10 controls for the expression of several angiogenesis-related miRNAs. miR21 was significantly up-regulated in tumor versus normal tissue, and was among the miRNAs with the largest expression difference between tumor tissue and normal 
samples. Though recent studies on its influence on angiogenesis suggest both pro- and antiangiogenic properties $[9,10]$, the involved mechanisms remains to be further investigated.

In our screening study [8] there was a four-fold change in tumor when compared to normal tissue when quantified by microarray hybridization and validated by realtime qPCR, but there was no significant difference between expressions in poor versus good prognostic cases. In fact, previously published results on the prognostic impact of miR-21 have been conflicting [11-15]. In cancer, the tumor stroma is, in addition to tumor cells, an important player in cancer development. Accordingly, miRNAs can be expressed differentially in tumor cells than in the surrounding stroma, and one speculate if its impact on prognosis could be different in the two compartments $[16,17]$. To further explore the prognostic impact of miR-21 in NSCLC we used ISH to facilitate, for the first time, evaluation of specific miR-21 expression in tumor cells and tumorsurrounding stromal cells, respectively.

In this study we aimed to investigate the prognostic impact of miR-21 in a large unselected NSCLC population. Since the impact of various angiogenic protein markers have been investigated in this cohort [18-20], we have also assessed the association between miR-21 and angiogenic markers.

\section{Methods}

\section{Patients and clinical samples}

Between 1990 and 2004, 371 patients with pathological stage I to IIIA non-small cell lung cancer were diagnosed at the University Hospital of North Norway and Nordland Central Hospital. Resected tissues from the primary tumors in these patients were used in our retrospective study. Out of 371 patients, 36 were excluded from the study due to radiotherapy or chemotherapy prior to surgery $(n=10)$, other malignancy within 5 years before NSCLC diagnosis $(n=13)$ or inadequate paraffin-embedded fixed tissue blocks $(\mathrm{n}=13)$. Adjuvant chemotherapy was not introduced in Norway during this period (1990 - 2004). Thus, 335 patients with complete demographic and clinicopathological data were eligible for this study.

This report includes follow-up data as of January 10, 2011. The median follow-up time of survivors was 105 months (range 73-234). Formalin-fixed, paraffin-embedded tumor specimens were obtained from the archives of the Departments of Clinical Pathology at the University Hospital of North Norway and Nordland Central Hospital. The pathological data were revised according to the 7th edition of UICC TNM classification of lung cancer [21]. The National Data Inspection Board and the Regional Committee for Research ethics approved this study.

\section{Microarray construction}

We used a $0.6 \mathrm{~mm}$-diameter stylet to sample two cores with neoplastic tissue and two cores with tumor stroma from different areas of the primary tumors from each patient. The tumor stroma consists of the nonmalignant cells of the tumor; activated fibroblasts, specialized mesenchymal cell types, innate and adaptive immune cells and the vasculature with endothelial cells and pericytes, as well as the extracellular matrix (ECM). Normal lung tissue localized distant from the tumor and lung tissue sample from 20 patients without cancer diagnosis were used as controls. The TMAs were assembled using a tissue-arraying instrument (Beecher Instruments, Silver Springs, MD, US). Eight tissue microarray blocks were made to include all the tissue samples. Multiple $4-\mu \mathrm{m}$-sections were cut with a Micron microtome (HM355S) and stained by specific antibodies for immunohistochemical analyses. The detailed methodology has been previously reported [20].

\section{In situ hybridization (ISH)}

In situ hybridization was performed following the protocol developed by Exiqon, Vedbaek, Denmark [22]. Digoxigenin (DIG) labeled locked nucleic acid (LNA) modified probes from Exiqon for miR-21 (hsa-miR-21), positive control (U6, hsa/mmu/rno) and negative control (scramble-miR) from Kit 2, miR-21, (90002, Exiqon) were used in this study. Some adjustments were done to get a specific and sensitive detection of miRNA in our sections from formalin-fixed paraffin-embedded (FFPE) TMA blocks.

We placed $4 \mu \mathrm{m}$ sections of the TMA blocks in a heater at $59^{\circ} \mathrm{C}$ over night to attach cores to Super Frost Plus slides. Sections were deparaffinised with xylene $(3 \times$ $5 \mathrm{~min}$.) and then rehydrated with ethanol solutions $(99.9 \%$ - 96\% - 70\%) ending up in PBS, pH 7.4. Proteinase-K $(20 \mu \mathrm{g} / \mathrm{ml})$ (Exiqon, Vedbaek, Denmark) treatment was done in PK-buffer $(5 \mathrm{mM}$ Tris. $\mathrm{HCl}, \mathrm{pH}$ 7.5, $1 \mathrm{mM}$ EDTA, $1 \mathrm{mM} \mathrm{NaCl}$, autoclaved) at $37^{\circ} \mathrm{C}$ for $20 \mathrm{~min}$ in a HYBrite automated hybridizer (Abbot laboratories, IL, US). After a PBS wash the sections were dehydrated through increasing gradient of ethanol solutions and air-dried. The LNA-probes were denatured by heating to $90^{\circ} \mathrm{C}$ for $4 \mathrm{~min}$. Hybridization of the LNAprobe miR-21 (50 nM) and scramble miR (50 nM) control was carried out in the HYBrite automated hybridizer at $50^{\circ} \mathrm{C}$ for $60 \mathrm{~min}$. The positive control U6 $(1 \mathrm{nM})$ was hybridized at $55^{\circ} \mathrm{C}$ for $60 \mathrm{~min}$. Stringent washes was performed in pre-heated SSC buffers, $1 \times 5 \mathrm{~min}$ in $5 \times$ SSC and $2 \times 5 \mathrm{~min}$ in $1 \times$ SSC and $0,2 \times$ SSC. Sections were blocked against unspecific binding in blocking solution from DIG wash and Block Buffer set (Roche, Mannheim, Germany) for $15 \mathrm{~min}$ at room temperature (RT). Alkaline phosphatase (AP)-conjugated anti-DIG 
(Roche) 1:800 was incubated for $60 \mathrm{~min}$ at RT for immunologic detection. After PBS-T wash the substrate enzymatic reaction was carried out with NBT/BCIP (Roche) at $30^{\circ} \mathrm{C}$ in the hybridizer for $120 \mathrm{~min}$. The reaction was stopped with a $2 \times 5$ min wash in KTBT buffer (50 mM Tris-Hcl, $150 \mathrm{mM} \mathrm{NaCl}, 10 \mathrm{mM} \mathrm{KCl}$ ). Counter stain with nuclear fast red (WALDECK, ZE-012-250) was done at RT for 1 min and then rinsed in tap water, dehydrated through increasing gradient of ethanol solutions and mounted with Histokitt mounting medium (Assistant-Histokitt, 1025/250).

\section{Immunohistochemistry (IHC)}

The detailed p-Akt Thr308 (rabbit monoclonal, clone 736E311, \#4056, Cell Signaling Technology, 1:50), Akt2 (rabbit monoclonal, clone 54G8, \#4057, Cell Signaling Technology, 1:18), Akt3 (rabbit polyclonal, \#4059, Cell Signaling Technology, 1:8), PI3K (rabbit polyclonal, \#4254, Cell Signaling Technology, 1:25), HIF1 $\alpha$ (mouse monoclonal, NB100-131, Novus Biological, 1:35000), and VEGF-A (rabbit polyclonal, RB-1678, Neomarkers, 1:10) IHC procedures has been previously published [18-20]. For each antibody, including negative controls, the TMA staining were done in a single experiment.

\section{Scoring of ISH and IHC}

The ARIOL imaging system (Genetix, San Jose, CA) was used to scan the TMA slides of ISH staining. The slides were loaded in the automated loader (Applied Imaging SL 50) and specimens were scanned at low $(1.25 \times)$ and high $(20 \times)$ resolution using the Olympus BX 61 microscope with automated platform (Prior). Representative and viable tissue sections were scored manually and semiquantitatively for cytoplasmic staining on a computer screen. The dominating staining intensity in tumor cells was scored as: $0=$ negative; 1 = weak; $2=$ intermediate; $3=$ strong (Figure 1). The tumor-related stroma was scored with one value from $0-3$ based on both staining intensity and cell density. We summarized the scores from tumor cells and stroma to get a total score which may be comparable to findings in other studies using RT-qPCR, where it not is discriminated between tumor and stromal expression. All cores were anonymized and independently scored by 2 experienced pathologists (S.A.S. and A.V.). When assessing a variable for a given core, the observers were blinded to the scores of the other observer and to outcome. In case of disagreement (score discrepancy $>1$ ), the slides was reexamined and a consensus was reached by the observers.

Mean score for each case was calculated from all 4 cores and both examiners. High expression of miR-21 in tumor cells was defined as a mean score $\geq 0.5$. For stroma, high expression was defined as positive values $(>0)$. For the angiogenic protein markers, the same cutoff values as previously published was used [18-20].

\section{Statistical methods}

All statistical analyses were performed using the statistical package SPSS (Chicago, IL), version 19.0. The chi-square test and the Fisher exact test were used to examine the association between molecular marker expression and the clinicopathological markers. Correlations between markers were assessed using Spearman's rank correlation. Plots of disease-specific survival (DSS) according to marker expression were drawn using Kaplan-Meier method, and statistical significance between survival curves was assessed by the log rank test. Variables of significant value from the univariate analyses were entered into multivariate analysis using the backward stepwise Cox regression analysis. A $\mathrm{P}<0.05$ was considered statistically significant.

\section{Results}

Patient characteristics

Demographic, clinical and histopathological variables are listed in Table 1. The median patient age was 67 (range $28-85$ ) and the majority were male (76\%). Most (95\%) were current or previous smokers. The NSCLC tumors comprised 191 squamous cell carcinomas (SCCs), 113 adenocarcinomas (ACs) including 18 bronchioalveolar carcinomas (BACs) and 31 large-cell carcinomas (LCCs).

\section{Expression of miR-21 and correlations}

miR-21 was expressed in the cytoplasm of tumor cells. The staining was mainly diffuse and partly granular. In tumor stroma, inflammatory cells, pneumocytes, fibroblasts and endothelial cells also showed mainly diffuse cytoplasmic staining.

There were no significant correlations between miR-21 and the angiogenesis-related markers Akt, PI3K, HIF1 $\alpha$ or VEGF-A. Neither were there any significant correlations when stratifying for nodal status (Table 2).

\section{Univariate analysis}

As shown in Table 1, the clinicopathological variables performance status $(P=0.016)$, histology $(P=0.028)$, tumor differentiation $(\mathrm{P}<0.001)$, surgical procedure $(\mathrm{P}=0.007)$, pathological stage $(\mathrm{P}<0.001)$, tumor status $(\mathrm{P}<0.001)$, nodal status $(\mathrm{P}<0.001)$ and vascular infiltration $(\mathrm{P}=0.001)$ were significant prognostic indicators for DSS.

The survival analysis for miR-21 is presented in Table 3 and Figure 2. Expression of miR-21 in the total cohort based on both tumor and stromal cells had no significant prognostic impact.

The situation was the same when only tumor cells were assessed. In subgroup analyses of lymph node positive patients, however, a high tumor miR-21 expression was significantly associated with an improved prognosis when compared to low expression $(P=0.024)$. This was not observed in lymph node negative patients $(\mathrm{P}=0.091)$. 


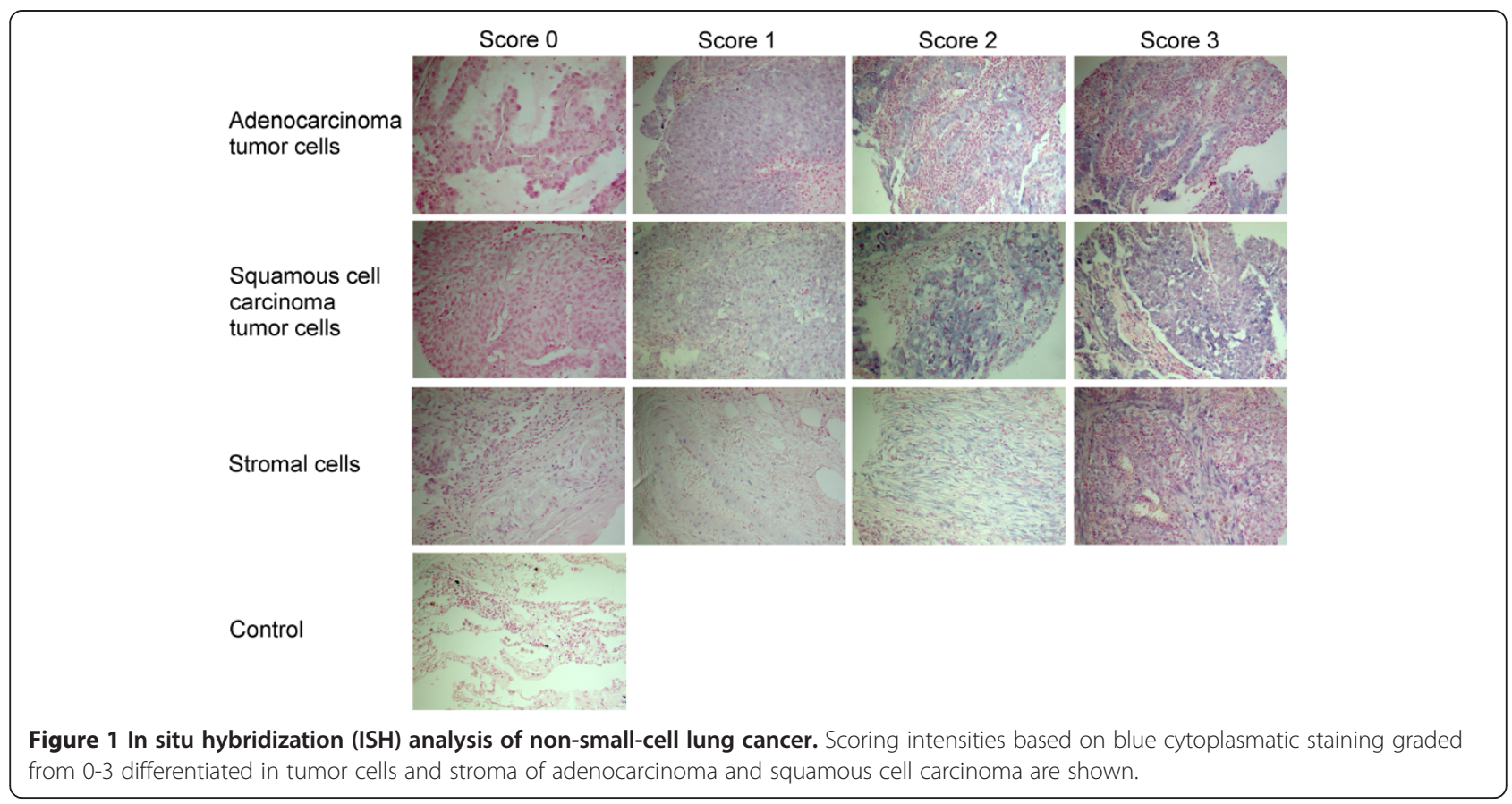

In stroma of all patients, high miR-21 expression was a negative prognostic indicator $(\mathrm{P}=0.022)$. This was also observed in the subgroup with node-negative disease, but not in node-positive patients.

\section{Multivariate analysis}

In the multivariate analysis the following clinicopathological variables appeared as independent prognostic variables: performance status $(\mathrm{P}=0.008)$, histology $(\mathrm{P}=$ $0.001)$, tumor differentiation $(\mathrm{P}=0.007)$, tumor status $(\mathrm{P}=0.007)$, nodal status $(\mathrm{P}=0.022)$ and vascular infiltration $(\mathrm{P}=0.004)$.

Results of the multivariate analyses for miR-21 expression are presented in Table 3. In analyses of the total material, all significant clinicopathological factors from the univariate analyses were included. For the $\mathrm{N}+$ subgroup, no relevant clinicopathological factors were significant in the univariate analysis. Tumor or stromal miR-21 expression in the total material had no independent prognostic impact. In node positive patients, however, low tumor miR-21 expression was an independent negative prognostic factor (HR 2.03, CI 95\% 1.09-3.78, $\mathrm{P}=0.027$ ).

\section{Discussion}

In a large unselected cohort, we have used highthroughput TMA-technique and in situ hybridization to evaluate the prognostic impact of miR-21 expression in tumor tissue and stroma of NSCLC. To our knowledge, we are the first to use ISH to study miR-21 expression and outcome in a large NSCLC cohort, facilitating analyses discriminating specifically between tumor cells and cells of the tumor stroma. We find high tumor miR-21 expression in node-positive patients to be an independent positive prognostic indicator. In univariate analyses, we find high stromal miR-21 expression to be a negative prognostic factor in the total material and in nodenegative patients. There was no correlation between miR-21 and angiogenesis-related markers.

miRNAs have a large impact on gene regulation, and are considered major players in tumor development and metastasis [3]. These nucleotides act as both oncogenes and tumor suppressor genes, as they may be both upand down-regulated in tumors. miR-21 is known to be abundantly expressed in a variety of cancers, and is in many tumor types associated with a reduced overall survival [2]. In a recent array screening study, including 20 NSCLC patients and 10 controls, we found miR-21 to be one of the most upregulated miRNAs in tumor tissue, when compared to normal tissue, by both microarray hybridization and quantitative real time polymerase chain reaction (qRT-PCR) technique [8].

In recent years, a few studies have explored the prognostic impact of miR-21 in NSCLC. Markou et al. studied 48 patients, where $67 \%$ where in stage I/II and $33 \%$ stage III/IV. They found miR-21 to be an independent negative prognostic factor for OS [13]. Gao et al. observed the same in 47 NSCLC samples. In their cohort, $47 \%$ were stage I, $25 \%$ stage II and $28 \%$ stage III, respectively [11]. In three cohorts from 
Table 1 Patient characteristics and their variables as predictors for disease-specific survival in 335 NSCLC patients (univariate analyses; log-rank test)

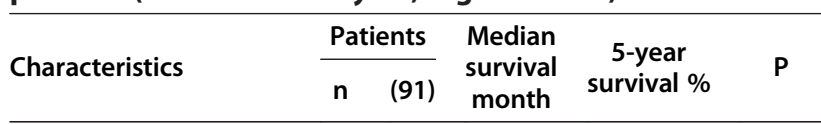

\section{Age}

$\leq 65$ years

$>65$ years

Sex

Female
Male

Smoking

Never

Current

Former

Performance status

PS 0

PS 2

Weight loss

$<10 \%$

$>10 \%$

Histology

SCC

Adenocarcinoma

LCC

Differentiation

Poor

Moderate

Well

Surgical procedure

Lobectomy + Wedge*

Pitunionectomy

Pathological stage

।

Tumor status

1
2
3

Nodal status

$\begin{array}{lccccc}0 & 232 & (69) & N R & 67 & \\ 1 & 76 & (23) & 35 & 43 & <0.001 \\ 2 & 27 & (8) & 18 & 18 & \end{array}$

Table 1 Patient characteristics and their variables as predictors for disease-specific survival in 335 NSCLC patients (univariate analyses; log-rank test) (Continued)

\begin{tabular}{lccccc}
\hline Surgical margins & & & & & \\
$\quad$ Free & $3) 7$ & $(92)$ & 190 & 59 & 0.37 \\
$\quad$ Not free & 28 & $(8)$ & 47 & 48 & \\
Vascular infiltration & & & & & \\
$\quad$ No & 284 & $(85)$ & 190 & 62 & $\mathbf{0 . 0 0 1}$ \\
Yes & 51 & $(15)$ & 27 & 33 & \\
\hline
\end{tabular}

*Wedge, $\mathrm{n}=10$.

Abbreviations: NR not reached, PS performance status, SCC squanos cell carcinoma, LCC large-cell carcinoma.

Statistically significant results in bold font.

0.26 Maryland, US (64\% stage I, 25\% stage II, $11 \%$ stage III), Norway (57\% stage I, $14 \%$ stage II, $29 \%$ stage III), and Japan (74\% stage I, 26\% stage II), Saito and colleagues showed miR-21 to be an independent negative prognostic factor. In the Norwegian and American material, overall survival was the endpoint, while in the Japanese cohort relapse free survival was [14]. Landi and colleagues used an oligo array with 440 human miRNAs to evaluate differences in miRNA expression depending on histology and clinical outcome in 290 NSCLC tissues, constituted by $40 \%$ stage I, $29 \%$ stage II, 26\% stage III and $4 \%$ stage IV cancers. They found miR-21 to differentiate between adenocarcinoma and squamous cell carcinoma, but there was no difference in survival according to miR-21 expression rate [12]. In a large study on 639 patients (35\% stage I, 23\% stage II and $42 \%$ stage III), Voortman et al. observed no prognostic impact of miR-21 on NSCLC survival. There was a tendency towards a better prognosis for high miR-21 expression, but this finding was not significant $(\mathrm{P}=0.06)$ [15].

There were some differences in methodology between these studies, as fresh frozen tissue was used in three $[11,13,14]$ and paraffin-embedded material in two studies $[12,15]$. For quantification of miRNA, all except the Landi study used qRT-PCR. In the studies where miR-21 was associated with a worse prognosis, subgroup analyses were not performed. The Landi and Gao studies $[11,12]$ were numerously too small and the Saito study consisting of three cohorts (89, 37 and 189 patients respectively) [14], was not suited for subgroup analyses.

Yang et al. performed a meta-analysis based on the studies mentioned above. They also included two other studies analyzing miR-21 in serum. The conclusion was that high miR-21 expression was significantly associated with poor survival [23].

When using the summarized score of tumor cell and stromal expression in the whole cohort, miR-21 was without any significant prognostic impact. In the stromal 
Table 2 Correlations between miR-21 expression and angiogenesis related markers

\begin{tabular}{|c|c|c|c|c|c|c|c|c|c|}
\hline \multirow[t]{2}{*}{ Molecular marker } & \multirow[b]{2}{*}{ Compartment } & \multicolumn{2}{|l|}{ Akt } & \multicolumn{2}{|l|}{$\mathrm{PI} 3 \mathrm{~K}$} & \multicolumn{2}{|l|}{ HIF1a } & \multicolumn{2}{|l|}{ VEGF-A } \\
\hline & & Tumor & Stroma & Tumor & Stroma & Tumor & Stroma & Tumor & Stroma \\
\hline \multicolumn{10}{|c|}{ A: Correlations in all 335 patients } \\
\hline \multirow[t]{2}{*}{ miR-21 } & Tumor & $P=0.700$ & & $P=0.488$ & & $P=0.687$ & & $P=0.751$ & \\
\hline & Stroma & & $P=0.217$ & & $P=0.655$ & & $P=0.251$ & & $P=0.622$ \\
\hline \multicolumn{10}{|c|}{ B: Correlations in 232 node-negative patients } \\
\hline \multirow[t]{2}{*}{ miR-21 } & Tumor & $P=0.736$ & & $P=0.566$ & & $P=0.473$ & & $P=0.945$ & \\
\hline & Stroma & & $P=0.692$ & & $P=473$ & & $P=0.685$ & & $P=0.272$ \\
\hline \multicolumn{10}{|c|}{ C: Correlations in 103 node-positive patients } \\
\hline \multirow[t]{2}{*}{ miR-21 } & Tumor & $P=0.735$ & & $P=0.701$ & & $P=0.751$ & & $P=0.685$ & \\
\hline & Stroma & & $P=0.112$ & & $P=0.722$ & & $P=0.144$ & & $P=0.192$ \\
\hline
\end{tabular}

Table 3 miR-21 in tumor cells and stroma as predictors for disease-specific survival in NSCLC patients (univariate analysis; log-rank test) and results of Cox regression analysis summarizing significant independent prognostic factors

\begin{tabular}{|c|c|c|c|c|c|c|c|}
\hline Characteristics & Pts (n) & Pts (\%) & Median survival (months) & 5-Year survival (\%) & Univariate $(\mathrm{P})$ & Multi-variate (P) & HR $95 \% \mathrm{Cl}$ \\
\hline Total $(n=335)$ & & & & & 0.45 & 0.71 & 1.08 \\
\hline Low & 220 & 66 & 190 & 61 & & & $0.73-1.60$ \\
\hline High & 98 & 29 & 98 & 55 & & & \\
\hline Missing & 17 & 5 & & & & & \\
\hline Tumor $^{1}(n=335)$ & & & & & 0.65 & 0.40 & 1.20 \\
\hline Low & 60 & 18 & NR & 59 & & & $0.74-1.95$ \\
\hline High & 258 & 77 & 127 & 59 & & & \\
\hline Missing & 17 & 5 & & & & & \\
\hline No $(n=223)$ & & & & & 0.091 & 0.33 & 0.69 \\
\hline Low & 43 & 19 & NR & 75 & & & $0.33-1.45$ \\
\hline High & 180 & 81 & 190 & 66 & & & \\
\hline$N+(n=95)$ & & & & & 0.024 & 0.027 & 2.03 \\
\hline Low & 17 & 18 & 17 & 18 & & & $1.09-3.78$ \\
\hline High & 78 & 82 & 37 & 42 & & & \\
\hline Stroma $^{2}(n=335)$ & & & & & 0.022 & 0.12 & 0.45 \\
\hline Low & 21 & 6 & 189 & 89 & & & $0.16-1.24$ \\
\hline High & 301 & 90 & 127 & 57 & & & \\
\hline Missing & 13 & 4 & & & & & \\
\hline No $(n=225)$ & & & & & 0.044 & 0.061 & 0.32 \\
\hline Low & 16 & 7 & 190 & 93 & & & $0.08-1.38$ \\
\hline High & 209 & 93 & NR & 66 & & & \\
\hline$N+(n=97)$ & & & & & 0.44 & 0.45 & 0.58 \\
\hline Low & 5 & 5 & 71 & 75 & & & $0.14-2.37$ \\
\hline High & 92 & 95 & 27 & 36 & & & \\
\hline
\end{tabular}

$\mathrm{NR}=$ not reached.

${ }^{1}$ Tumor cells.

${ }^{2}$ Cells of the peritumoral connective tissue (fibroblasts, mesenchymal cells, immune cells, endothelial cells, pericytes and extracellular matrix.

Statistically significant results in bold font. 

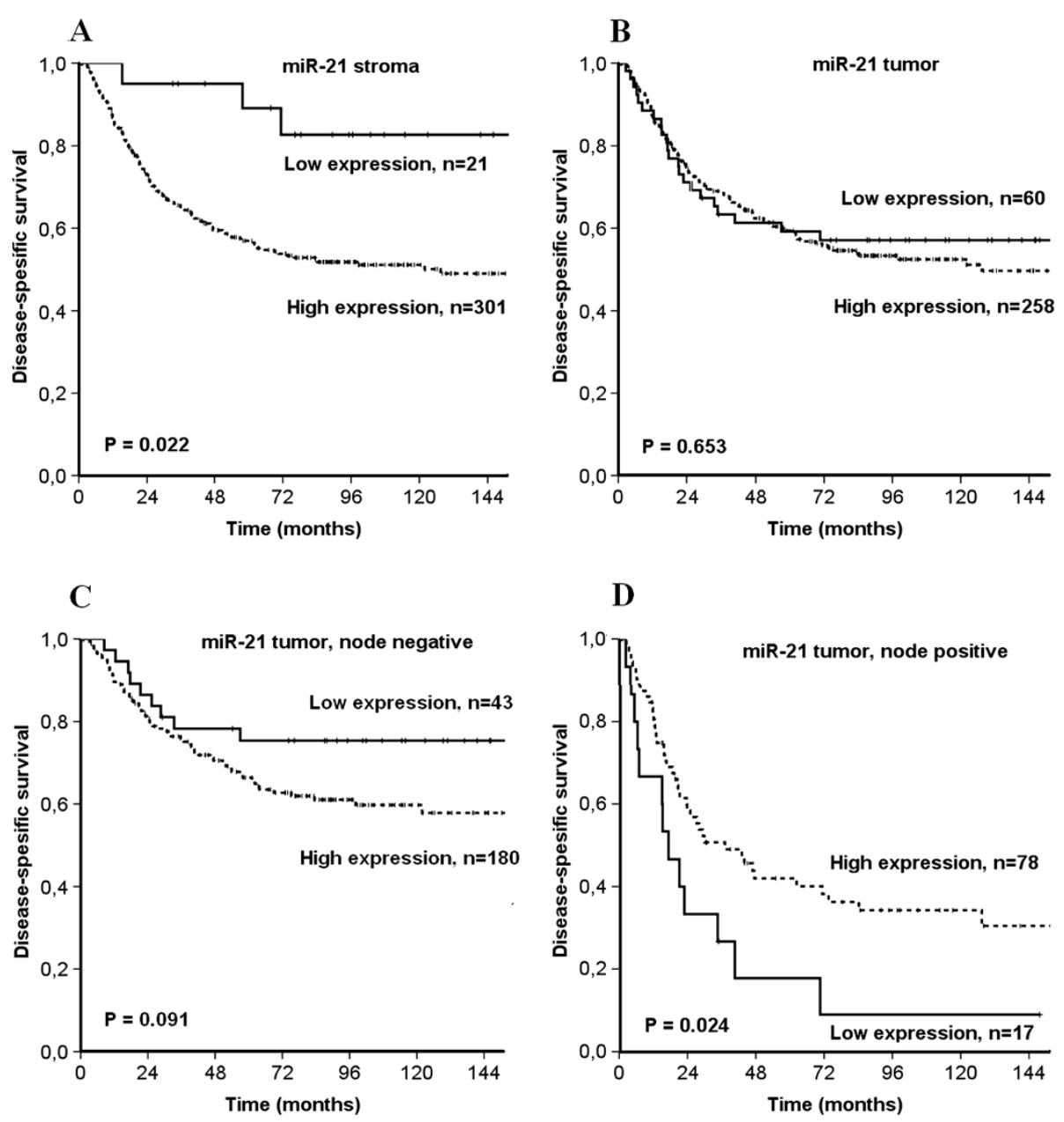

Figure 2 Disease-specific survival curves according to expression of A) miR-21 in stroma, B) miR-21 in tumor, C) miR-21 in tumor in node negative patients and D) miR-21 in tumor in node positive patients.

compartment, miR-21 expression was a negative prognosticator in univariate, but not in the multivariate analysis. In the studies mentioned above $[11,13,14]$, except for the studies by Voortman [15] and Landi [12], miR-21 appears to be a negative prognostic factor in NSCLC, corroborating our stromal results. In contrast, we found miR-21 expression in tumor cells to be an independent positive prognostic factor in node positive lung cancer patients. One may speculate if the differences we observe between our results and some of the other studies are caused by the different methodologies used. As we use ISH-technique, miR-21 expression can be assessed separately in tumor and stromal cells. When using the qRT-PCR method without prior microdissection, it can not be differentiated between the tumor cells and the stromal compartment. Gregg and colleagues performed microdissection on a prostate cancer material to separate tumor and stromal cells, and showed a large difference regarding gene expression between the two compartments [24]. Our findings show that there is a prognostic difference in expression between the two compartments. Using qRT-PCR the contribution of miR21 from the stromal compartment may override the contribution from tumor cells, especially at significant differences in expression. Consequently, the data will reflect the situation in stroma, and a divergent situation in the tumor cells will not be detected. The conclusion in the Yang meta-analysis reflects the findings in these studies, and does not take into account possible expression differences between the compartments.

The mechanistic functions of miR-21 are still being explored, but some functions have recently been suggested. In human umbilical vein endothelial cells (HUVECs), Sabatel and colleagues found miR-21 to be a potential inhibitor of angiogenesis via inhibition of RhoB, resulting in a reduction in endothelial proliferation, migration and vessel formation [10]. On the other hand, Liu et al. demonstrated miR-21 to induce angiogenesis in human 
prostate cancer cells through up-regulating HIF-1 $\alpha$ and VEGF and through activating the Akt and ERK pathways [9]. Hence, miR-21 may have both pro- and antiangiogenic functions. Angiogenesis is an important trait of cancer progression [25], and inhibiting angiogenesis may contribute to slow down cancer growth. In the light of these opposing findings and our data, we may speculate if miR-21 has opposite impacts in different stages of the disease. Could high miR-21 in early stages (nodenegative) act pro-angiogenic and contribute to a faster progression, while in a node positive stage, it acts antiangiogenic and protects against further progression?

We did not find any correlations between miR-21 and angiogenic markers of pathways earlier described for miR-21 and angiogenesis $[9,10]$. These pathways are possibly tissue and cell type specific. Studies exploring miR21 as a modulator of angiogenesis have in some cases used endothelial cells in their models [10]. In our material, we have not specifically studied endothelial cells, so the connection between miR-21 and angiogenetic markers seen in endothelial cells will not necessarily be mirrored by our tissue samples as we assessed the sum off all stromal cell types.

\section{Conclusion}

We found tumor cell miR-21 expression to be an independent positive prognostic factor in node-positive NSCLC. In the total material, stromal miR-21 expression was a negative prognostic factor in univariate analysis. We identified diverging impacts of miR-21 related to cell compartment and nodal status. These findings should be further explored, and may have implications for the future use of miR-21 in diagnostics and therapy.

\section{Competing interests}

The authors declare that they have no competing interests.

\section{Authors' contributions}

HS participated in the design of the study, contributed to the clinical and demographic database, did the statistical analysis and drafted the manuscript. TD, SA and SAS contributed to the clinical and demographic database and SAS and MIP in making the TMAs. TD and SA contributed to the statistical analysis. SAS and AV scored the cores. MIP carried out the ISH. RB and LTB supervised and participated in the study design, result interpretation and writing. All authors read and approved the final manuscript.

\section{Acknowledgements}

The study was solely funded by the Northern Norway Regional Health Authority (Helse Nord RHF) which is responsible for the public hospitals in northern Norway. The funders had no role in study design, data collection and analysis, decision to publish, or preparation of the manuscript.

\footnotetext{
Author details

${ }^{1}$ Institute of Clinical Medicine, University of Tromso, Tromso, Norway. ${ }^{2}$ Department of Oncology, University Hospital of North Norway, Tromso 9038, Norway. ${ }^{3}$ Institute of Medical Biology, University of Tromso, Tromso, Norway. ${ }^{4}$ Dept of Clinical Pathology, University Hospital of North Norway, Tromso, Norway.
}

Received: 16 May 2013 Accepted: 27 January 2014

Published: 13 February 2014

\section{References}

1. Jemal A, Siegel R, Xu J, Ward E: Cancer statistics, 2010. CA Cancer J Clin 2010, 60:277-300.

2. Fu X, Han Y, Wu Y, Zhu X, Lu X, Mao F, et al: Prognostic role of microRNA21 in various carcinomas: a systematic review and Meta-analysis. Eur J Clin Invest 2011, 41:1245-53.

3. Iorio MV, Croce CM: MicroRNAs in cancer: small molecules with a huge impact. J Clin Oncol 2009, 27:5848-5856.

4. Kasinski AL, Slack FJ: Epigenetics and genetics. MicroRNAs en route to the clinic: progress in validating and targeting microRNAs for cancer therapy. Nat Rev Cancer 2011, 11:849-864.

5. Krichevsky AM, Gabriely G: miR-21: a small multi-faceted RNA. J Cell Mol Med 2009, 13:39-53.

6. Olson P, Lu J, Zhang H, Shai A, Chun MG, Wang Y, et al: MicroRNA dynamics in the stages of tumorigenesis correlate with hallmark capabilities of cancer. Genes Dev 2009, 23:2152-2165.

7. Suarez $Y$, Sessa WC: MicroRNAs as novel regulators of angiogenesis. Circ Res 2009, 104:442-454.

8. Donnem T, Fenton CG, Lonvik K, Berg T, Eklo K, Andersen S, et al: MicroRNA Signatures in Tumor Tissue Related to Angiogenesis in Non-Small Cell Lung Cancer. PLoS One 2012, 7:e29671.

9. Liu LZ, Li C, Chen Q, Jing Y, Carpenter R, Jiang Y, et al: MiR-21 induced angiogenesis through AKT and ERK activation and HIF-1alpha expression. PLoS One 2011, 6:e19139.

10. Sabatel C, Malvaux L, Bovy N, Deroanne C, Lambert V, Gonzalez ML, et al: MicroRNA-21 exhibits antiangiogenic function by targeting RhoB expression in endothelial cells. PLoS One 2011, 6:e16979.

11. Gao W, Yu Y, Cao H, Shen H, Li X, Pan S, et al: Deregulated expression of miR-21, miR-143 and miR-181a in non small cell lung cancer is related to clinicopathologic characteristics or patient prognosis. Biomed Pharmacother 2010, 64:399-408.

12. Landi MT, Zhao Y, Rotunno M, Koshiol J, Liu H, Bergen AW, et al: MicroRNA expression differentiates histology and predicts survival of lung cancer. Clin Cancer Res 2010, 16:430-441.

13. Markou A, Tsaroucha EG, Kaklamanis L, Fotinou M, Georgoulias V, Lianidou ES: Prognostic value of mature microRNA-21 and microRNA205 overexpression in non-small cell lung cancer by quantitative real-time RT-PCR. Clin Chem 2008, 54:1696-1704.

14. Saito M, Schetter AJ, Mollerup S, Kohno T, Skaug V, Bowman ED, et al: The association of microRNA expression with prognosis and progression in early-stage, non-small cell lung adenocarcinoma: a retrospective analysis of three cohorts. Clin Cancer Res 2011, 17:1875-1882.

15. Voortman J, Goto A, Mendiboure J, Sohn JJ, Schetter AJ, Saito M, et al: MicroRNA expression and clinical outcomes in patients treated with adjuvant chemotherapy after complete resection of non-small cell lung carcinoma. Cancer Res 2010, 70:8288-8298.

16. Dillhoff M, Liu J, Frankel W, Croce C, Bloomston M: MicroRNA-21 is overexpressed in pancreatic cancer and a potential predictor of survival. J Gastrointest Surg 2008, 12:2171-2176.

17. Nielsen BS, Jorgensen S, Fog JU, Sokilde R, Christensen IJ, Hansen U, et al: High levels of microRNA-21 in the stroma of colorectal cancers predict short disease-free survival in stage II colon cancer patients. Clin Exp Metastasis 2011, 28:27-38.

18. Andersen S, Eilertsen M, Donnem T, Al-Shibli K, Al-Saad S, Busund LT, et al: Diverging prognostic impacts of hypoxic markers according to NSCLC histology. Lung Cancer 2011, 72:294-302.

19. Al-Saad S, Donnem T, Al-Shibli K, Persson M, Bremnes RM, Busund LT: Diverse prognostic roles of Akt isoforms, PTEN and PI3K in tumor epithelial cells and stromal compartment in non-small cell lung cancer. Anticancer Res 2009, 29:4175-4183.

20. Donnem T, Al-Saad S, Al-Shibli K, Delghandi MP, Persson M, Nilsen MN, et al Inverse prognostic impact of angiogenic marker expression in tumor cells versus stromal cells in non small cell lung cancer. Clin Cancer Res 2007, 13:6649-6657.

21. Rami-Porta R, Chansky K, Goldstraw P: Updated lung cancer staging system. Future Oncol 2009, 5:1545-1553. 
22. Jorgensen S, Baker A, Moller S, Nielsen BS: Robust one-day in situ hybridization protocol for detection of microRNAs in paraffin samples using LNA probes. Methods 2010, 52:375-381.

23. Yang M, Shen H, Qiu C, Ni Y, Wang L, Dong W, et al: High expression of miR-21 and miR-155 predicts recurrence and unfavourable survival in non-small cell lung cancer. Eur J Cancer 2012, 49:604-15.

24. Gregg JL, Brown KE, Mintz EM, Piontkivska H, Fraizer GC: Analysis of gene expression in prostate cancer epithelial and interstitial stromal cells using laser capture microdissection. BMC Cancer 2010, 10:165.

25. Hanahan D, Weinberg RA: Hallmarks of cancer: the next generation. Cell 2011, 144:646-674.

doi:10.1186/1472-6890-14-9

Cite this article as: Stenvold et al:: High tumor cell expression of microRNA-21 in node positive non-small cell lung cancer predicts a favorable clinical outcome. BMC Clinical Pathology 2014 14:9.

\section{Submit your next manuscript to BioMed Central and take full advantage of:}

- Convenient online submission

- Thorough peer review

- No space constraints or color figure charges

- Immediate publication on acceptance

- Inclusion in PubMed, CAS, Scopus and Google Scholar

- Research which is freely available for redistribution 